\title{
The use of modern telemedicine technologies in an innovative optimal cardiac rehabilitation program for patients after myocardial revascularization: Concept and design of RESTORE, a randomized clinical trial
}

Krzysztof Milewski ${ }^{1,2}$, Andrzej Małecki ${ }^{2}$, Dominika Orszulik-Baron ${ }^{1}$, Mateusz Kachel ${ }^{1}$, Piotr Hirnle ${ }^{1}$, Marek Orczyk ${ }^{1,2}$, Rafał Dunal ${ }^{4}$, Grzegorz Mikołajowski ${ }^{2}$, Adam Janas ${ }^{1}$, Zbigniew Nowak ${ }^{2}$, Karol Kozak ${ }^{5}$, Wojciech Roskiewicz ${ }^{6}$, Katarzyna Nierwińska ${ }^{2}$, Andrzej Izworski ${ }^{7}$, Adam Rybicki ${ }^{8}$, Piotr P. Buszman ${ }^{1,3}$, Ryszard Piotrowicz ${ }^{9}$, Pawel E. Buszman ${ }^{1,3}$

${ }^{1}$ Center for Cardiovascular Research and Development, American Heart of Poland, Katowice, Poland; ${ }^{2}$ The Jerzy Kukuczka Academy of Physical Education, Katowice, Poland; ${ }^{3}$ Andrzej Frycz Modrzewski Krakow University, Faculty of Medicine and Health Sciences, Krakow, Poland; ${ }^{4}$ Silvermedia, Krakow, Poland; ${ }^{5}$ Universitätsklinikum Carl Gustav Carus, Dresden, Germany; ${ }^{6}$ Fraunhofer-Gesellschaft zur Förderung der Angewandten Forschung e.V., München, Germany; ${ }^{7}$ AGH University of Science and Technology, Krakow, Poland; ${ }^{8}$ Uzdrowisko Ustron Health Resort, Poland; ${ }^{9}$ Head of Department of Cardiac Rehabilitation and Noninvasive Electrocardiology, National Institute of Cardiology, Warsaw, Poland

\begin{abstract}
Despite proven efficacy of cardiac rehabilitation (CR) in reducing the all-cause mortality in patients after myocardial revascularization, the penetration of $C R$, due to patient-related factors and referral rates remains limited. To improve the outcomes, home-based tele-rehabilitation (TR) has been proposed recently. In theory $T R$ enhances the effects of standard CR procedures due to implementation of an intelligent monitoring system designed to ensure optimal training through on-demand transmission of vital signs, aimed at motivating the patients through daily schedule reminders, setting daily goals and creating a platform for mutual feedback. Several meta-analyses assessing various studies comparing these two methods (CR and TR) have proven that they are at least equally effective, with some of the research showing superiority of TR. Although there was a small sample size, lack of long-term follow-up, reporting effects of TR itself, no integration with tools designed for coaching, motivating and promoting a healthy lifestyle constitutes an important limitation. The latter carries a hopeful prognosis for improvement when utilizing a broad-spectrum approach, especially with use of dedicated technological solutions exploiting the fact of a large and yet rapidly increasing penetration of smartphones, mobile $P C s$ and tablets in the population. The above-mentioned findings worked as the basis and rationale for commencing the RESTORE project aimed at developing and delivering state-of-the-art, comprehensive $T R$ for patients after myocardial revascularization and evaluating its molecular aspect in view of how it influences the atherosclerosis progression attenuation. This paper presents the current state and rationale behind the project based on up-to-date TR efficacy data. (Cardiol J 2019; 26, 5: 594-603)
\end{abstract}

Key words: tele-rehabilitation, myocardial revascularization, optimal cardiac rehabilitation, reduced rehospitalization rate

Address for correspondence: Krzysztof Milewski, MD, PhD, Center for Cardiovascular Research and Development, American Heart of Poland Inc., ul. Czajek 41, Katowice, Poland, tel: +48 609109131, fax: +48 334722911,

e-mail:k.milewski@ahp-ccrd.org

Received: 25.09.2018 Accepted: 8.11.2018 


\section{Introduction}

The worldwide prevalence of cardiovascular diseases (CVD) has been increasing during the last few decades, and is the main cause of mortality in Europe with 3.9 million deaths each year according to European Cardiovascular Disease Statistics 2017 , it also generates a staggering cost of $€ 210$ billion a year [1]. Coronary artery disease (CAD) accounts for $45 \%$ of all deaths from CVD and is the single most prominent cause of mortality [1]. With recent advances in diagnostics and therapy of $\mathrm{CAD}$, including percutaneous coronary interventions (PCI) with new generation stent implantation, modern pharmacotherapy and minimally invasive surgical procedures, patient survival has improved, although long-term prognosis remains unsatisfactory. For instance, 1-year mortality following myocardial infarction (both ST-segment elevation myocardial infarction [STEMI] and non-ST-segment elevation myocardial infarction [NSTEMI]) in Poland, based on nationwide AMI-PL database was as high as $19.4 \%$ [2]. The increased risk of cardiac events is further associated with a high frequency of hospital re-admissions, resulting in a serious quality of life issue and negative economic impact. To reduce the risk and improve prognosis, the treatment strategy should not be limited to on-site intervention but encompass a full range of actions directed to ensure a complete recovery and long-term maintenance. Current European Society of Cardiology (ESC) guidelines recommend prompt implementation of extensive cardiac rehabilitation (CR) for all patients with ST-elevation acute myocardial infarction (Class I, Level B), NSTEMI (Class IIa, Level A) and stable coronary artery disease (Class I, Level A) [3]. The benefits of CR as a method of secondary prevention for patients with CAD are widely known and well documented. Numerous studies have demonstrated that CR is associated with significant reduction in all-cause mortality in patients after myocardial revascularization [4-7]. Ten-year follow-up analysis in patients who underwent percutaneous intervention due to acute coronary syndrome showed an almost $40 \%$ decrease in mortality in a group of CR patients in comparison to non-CR patients ( $14.7 \%$ vs. $23.5 \%)$ [8]. Further potential advantages include reduction in symptoms, improvement in exercise tolerance and physical work capacity, improvement in psychosocial well-being, quality of life and stress management, attenuation of the atherosclerotic processes, decreased risk of subsequent coronary events and revascularization, and a reduced frequency of hospital readmission. Despite undisputed benefits, due to patient-related factors and referral rates, CR penetration remains limited [9]. In European countries less than one-half of the coronary patients access cardiac prevention and rehabilitation programs [10]. Similar numbers occur in the population of the United States [11-13]. The most significant patient-related barriers encompass lack of resources, attitude problems, differences in geographic distribution of stationary rehabilitation centers among regions resulting in long distances, restrictions in access to appropriate services as well as reimbursement issues. Additionally, CR participation is further impaired by a failure to motivate patients to lifestyle changes, coupled with an inability to track progress and efficacy of rehabilitation programs. The major disadvantage of current $\mathrm{CR}$ programs is their relatively short duration without long-term follow-up, which discourages the development of sustainable changes in a patients' lifestyle. To improve outcomes, home-based tele-rehabilitation (TR) has been proposed recently. In theory TR enhances the effects of standard $\mathrm{CR}$ procedures due to the implementation of an intelligent monitoring system designed to ensure optimal training through on-demand transmission of vital signs such as electrocardiogram (ECG) and both the physical and mental state of patients. Moreover, it aims to motivate patients, reminding them of scheduled activities, setting daily goals, creating a platform for mutual feedback and thus promote shaping of new habits. Several meta-analyses assessing various studies comparing these two methods (CR and TR) have proven that they are at least equally effective, with some of the research showing a superiority of TR in terms of the frequency of adverse events, rehospitalization rate, physical activity levels, adherence to physical activity guidelines and both low-density lipoprotein and diastolic blood pressure levels (Table 1) [14-17]. However, significant limitations of a greater proportion of the studies were the relatively small sample size, lack of long-term follow-up and reporting effects of TR itself, lack of integration with tools designed for coaching, motivating the patient and promoting a healthy lifestyle. The latter carries a hopeful prognosis for improvement when utilizing a broadspectrum approach, especially the use of dedicated technological solutions which exploit a large and yet rapidly increasing penetration of smartphones, mobile PCs and tablets in the population. Additionally, the lack of guidelines in this matter further highlights the need for large randomized studies 
Table 1. Comparison between tele-rehabilitation and center-based rehabilitation programs (based on review analyses).

\begin{tabular}{|c|c|c|c|c|c|}
\hline Author & Year & $\begin{array}{l}\text { Type } \\
\text { of study }\end{array}$ & $\begin{array}{l}\text { No. of trials/ } \\
\text { /patients }\end{array}$ & $\begin{array}{l}\text { Primary } \\
\text { endpoint }\end{array}$ & $\begin{array}{c}\text { Additional } \\
\text { observations }\end{array}$ \\
\hline $\begin{array}{l}\text { Frederix et al. } \\
{[14]}\end{array}$ & 2015 & $\begin{array}{l}\text { Systematic } \\
\text { review }\end{array}$ & 37 trials & $\begin{array}{l}\text { Impact on adverse } \\
\text { events and RR: } \\
\text { Favors TR } \\
(1.30[1.13-1.50])\end{array}$ & $\begin{array}{c}\text { Adherence to } \\
\text { physical activity: } \\
\text { Favors TR } \\
\text { (0.56 [0.45-0.69]) }\end{array}$ \\
\hline $\begin{array}{l}\text { Huang et al. } \\
\text { [16] }\end{array}$ & 2015 & $\begin{array}{l}\text { Systematic } \\
\text { review }\end{array}$ & $\begin{array}{c}9 \text { trials/1546 } \\
\text { patients }\end{array}$ & $\begin{array}{l}\text { No statistical } \\
\text { difference in } \\
\text { all-cause mortality }\end{array}$ & $\begin{array}{c}\text { Comparable in exercise } \\
\text { capacity, lipid profile, } \\
\text { QoL, BP }\end{array}$ \\
\hline $\begin{array}{l}\text { Hwang et al. } \\
\text { [17] }\end{array}$ & 2015 & $\begin{array}{l}\text { Systematic } \\
\text { review }\end{array}$ & 11 trials & $\begin{array}{l}\text { No difference in } \\
\text { exercise capacity } \\
\text { expressed as 6MWD } \\
\text { and VO2 peak }\end{array}$ & $\begin{array}{l}\text { Higher adherence rates } \\
\text { of TR compared to CBR, } \\
\text { no difference in QoL }\end{array}$ \\
\hline $\begin{array}{l}\text { Rawstorn et al. } \\
\text { [15] }\end{array}$ & 2016 & $\begin{array}{l}\text { Systematic } \\
\text { review }\end{array}$ & $\begin{array}{l}11 \text { trials/1189 } \\
\text { patients }\end{array}$ & $\begin{array}{l}\text { Physical activity } \\
\text { level and exercise } \\
\text { adherence: } \\
\text { Both favors TR } \\
(0.42[0.21-0.64] \\
\S 0.75(28))\end{array}$ & $\begin{array}{c}\text { TR and CBR were comparably } \\
\text { effective for improving } \\
\text { maximal aerobic } \\
\text { exercise capacity } \\
\text { and other modifiable } \\
\text { CV risk factors }\end{array}$ \\
\hline
\end{tabular}

Statistical results presented as: odds ratio [95\% confidence interval]. $6 \mathrm{MWD}-6$-minute walk distance; BP - blood pressure; CBR - centerbased rehabilitation; CV — cardiovascular; QoL — quality of life; RR - rehospitalization rate; TR - tele-rehabilitation

to be conducted. The above-mentioned findings worked as a basis and rationale for commencing the RESTORE project aimed at developing and delivering state-of-the-art, comprehensive TR for patients after myocardial revascularization. The project is substantially funded by the Polish National Centre for Research and Development. The project obtained local bioethics committee approval (Bioethics Committee in Bielsko-Biala; approval no. 2016/02/11/05).

\section{Clinical Trial Information}

Utilization of Telemedicine in Optimal Cardiac Rehabilitation Program in Patients After Myocardial Revascularization (RESTORE); NCT03375944; https://clinicaltrials.gov/ct2/show/NCT03375944.

\section{Restore project}

\section{Objectives}

The aim of the RESTORE project was to determine an optimal cardiac rehabilitation (OCR) strategy using novel medical technologies and ensuring comprehensive $\mathrm{CR}$ through effective patient monitoring utilizing a remotely controlled $\mathrm{CR}$ program to decrease annual mortality and risk of cardiovascular events in CAD patients at 9 and 12-month follow-up (with an expected decrease to fall below $0.5 \%$ ). Additionally, an intensive dietary and educational program focused on lifestyle and risk factor modification to be implemented. As a novelty, the intravascular imaging with atherosclerotic plaque and intraarterial lipid characterization combined with a molecular aspect of OCR will also be evaluated in view of how it influences atherosclerosis progression attenuation. Primary endpoint will be maximum lipid core burden index (LCBI; $4 \mathrm{~mm}$ ) and secondary endpoints (among others): change in the amount of LCBI and change in the angle of lipid core.

Combining all these components should help to establish new strategies translating into up-todate CR and secondary prevention of cardiovascular events. To properly initiate and conduct this study the RESTORE Consortium has been created, consisting of prime Polish and European science and industry representatives led by American Heart of Poland SA.

\section{Methodology}

The project was split into key phases. The stepwise approach will ensure that any problems encountered during the study will be identified and resolved quickly, allowing timely execution of the project.

The first and crucial part of the project will be to design and build the platform of optimal home-based cardiac TR. The platform will consist of four critical and synchronized elements that enable fluent, efficient and safe operation of the 


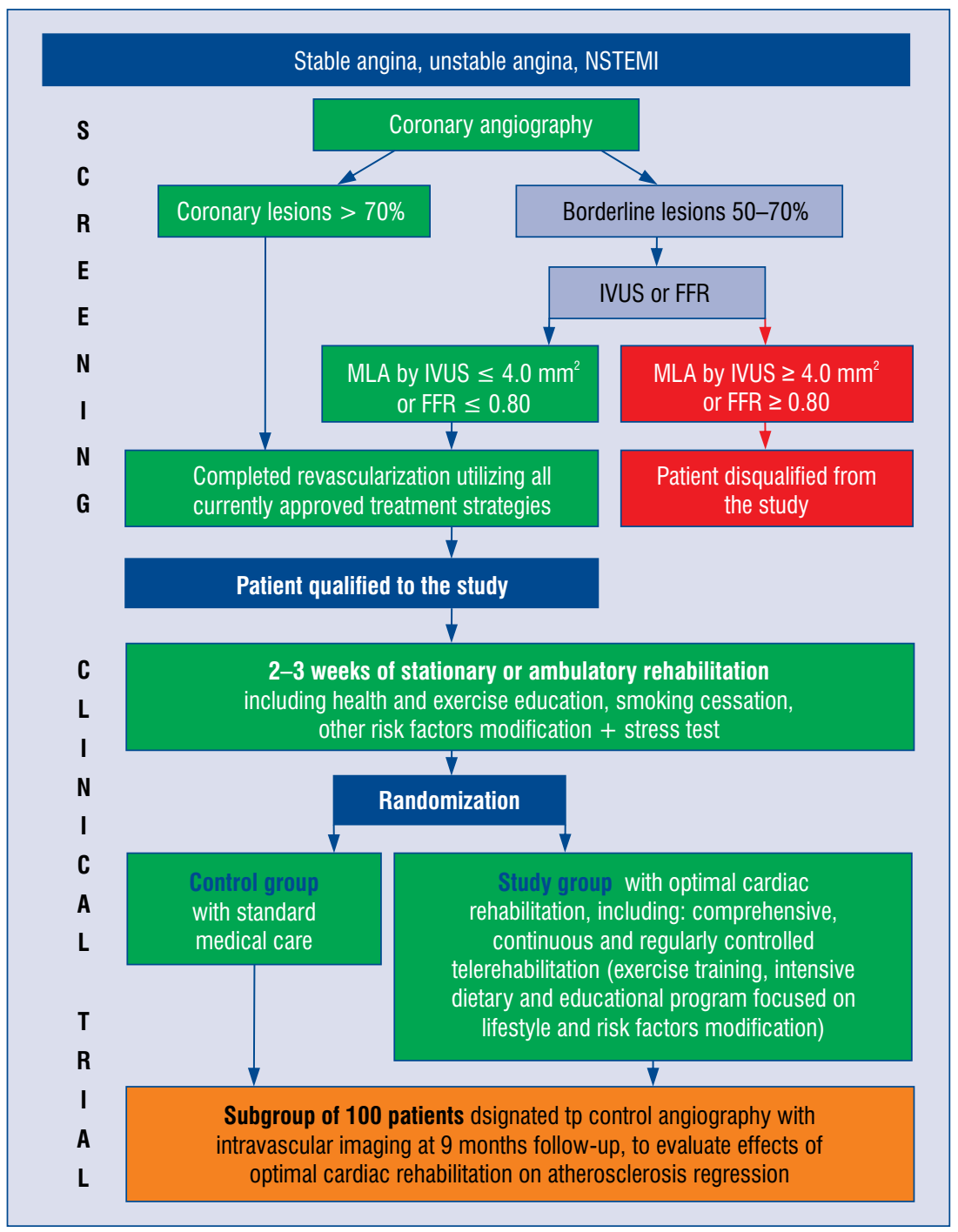

Figure 1. RESTORE randomized trial schematics; STEMI - ST-segment elevation myocardial infarction; IVUS — intravascular ultrasound; FFR — fractional flow reserve; MLA — minimal lumen area.

whole system. The elements include: (1) dedicated software for remote patient monitoring, which will be based on algorithms that allow automatic analysis of physiological signals; (2) peripheral medical devices that measure physiological signals including ECG, heart rate, and blood pressure; (3) a central system (coordinating center) that collects physiological parameters and to help medical staff and implemented algorithms allowing for rapid action in order to improve patient safety; (4) mobile applications which help patients manage their health status and allow for data transmission between medical devices and central system. Once all these devices are established and technological requirements met, the technical tests will be conducted. After positive testing, progression to the next phase and use of the system in a clinical setting will be enabled.
The next step is comprised of a prospective and randomized multi-center study including 5 cardiology units located in the Polish cities of Tychy, Bielsko-Biala, Dabrowa, Ustron, Chrzanow (Fig. 1). All patients enrolled in the study must be younger than 70 years old, presenting with stable or non-ST-elevation acute coronary syndrome (including NSTEMI and unstable angina) and must have completed coronary revascularization with any available method including coronary angioplasty, coronary artery bypass grafting or hybrid procedures. All lesions of $\geq 70 \%$ of diameter stenosis will be considered significant. If a lesion is assessed as $50-70 \%$ of diameter stenosis, additional imaging (intravascular ultrasound or optical coherence tomography) or functional (fractional flow reserve) tests will be performed at the physician's discretion in order to confirm the significance 
Table 2. Inclusion and exclusion criteria.

\begin{tabular}{ll}
\hline Inclusion criteria & Exclusion criteria \\
\hline Age over 18 and under 70 & Ejection fraction $<40 \%$ \\
$\begin{array}{l}\text { Completed revascularization } \\
\text { in patients with stable, unstable } \\
\text { angina or after NSTEMI }\end{array}$ & Acute myocardial infarction with ST segment elevation/new onset of LBBB \\
Eligibility to participate in a program & Suboptimal (not completed) myocardial revascularization \\
of early cardiac rehabilitation & Acute heart failure (Killip IV) at the time of admission to the hospital \\
The ability to use tele-rehabilitation & Dual antiplatelet therapy cannot be maintained for 1 year after PCl \\
system & Hemorrhagic stroke in the past \\
Signed informed consent form & Ischemic stroke or transient ischemia in previous 6 weeks \\
& Platelet count $<100,000 / \mathrm{mm}^{3}$ \\
& Chronic renal failure with creatinine clearance $<30 \mathrm{~mL} / \mathrm{min}^{\prime} / 1.73 \mathrm{~m}^{2}$ \\
& Planned surgery \\
& Pregnancy or planned pregnancies \\
& Expected life expectancy less than 3 years after enrollment \\
\hline
\end{tabular}

LBBB — left bundle branch block; NSTEMI — non-ST-segment elevation myocardial infarction; PCI — percutaneous coronary intervention

of stenosis. In patients following myocardial infarction with extensive scar tissue, the imaging tests were performed in order to assess viability before assigning any patient for the study. In addition, all patients must have ejection fraction equal or above 40\%. The main inclusion and exclusion criteria are presented in Table 2. After revascularization was completed all patients will undergo 2 to 3 weeks of stationary (in-hospital) or outpatient (ambulatory) CR. This allows enough time for health and exercise education, smoking cessation and other risk factor modifications. At the end of this period all patients will undergo a stress test, which will be then repeated at 9-month follow-up. During stationary or ambulatory rehabilitation all patients will be randomized to one of the following groups: (A) control group with standard medical care - optimal medical therapy, regular check-ups $(\mathrm{n}=500)$ or $(\mathrm{B})$ study group with optimal, remotely controlled and intense $\mathrm{CR}(\mathrm{n}=500)$. Before randomization, all patients $(\mathrm{n}=1000)$ will undergo technical training in order to get familiar with the TR program and medical devices provided. Patient number justification is based on the following assumption: at least 630 patients are required to have a $90 \%$ chance of detection, and be significant at the $5 \%$ level, a decrease in the primary outcome measure from $4.5 \%$ in the control group [18] to $0.5 \%$ in the experimental group. Taking into account previous reports on adherence rates to regular physical exercise it was decided to increase the number of patients to 500 per group.

Additionally, a subgroup of 100 patients (50 in the study group and 50 in the control arm) in whom, based on angiography, vessels with borderline lesion was left untreated, will undergo combined intravascular imaging with intravascular ultrasound (IVUS) and near-infrared spectroscopy (NIRS) using the commercially available TVC Imaging System $^{\mathrm{TM}}$ (Infraredx, Inc., Burlington, MA, USA) immediately following the last procedure and at 9-month follow-up (Fig. 2). The imaging will track potential changes in atherosclerotic plaque volume and composition (including the amount of intraarterial lipids) after optimal CR. The quantitative and qualitative analysis will be performed in independent core laboratory. Furthermore, a group of 100 patients will be qualified to take part in an additional molecular sub-study in which selected particles and processes, that potentially could change following physical activity and the rehabilitation program will be evaluated. This includes, among other factors, the activity and level of antioxidative enzymes, signs of oxidative damage to proteins, the expression of gene encoding enzymes involved in the defense against oxidative stress and markers of blood-brain-barrier integrity. Polymorphism of genes related to endothelial and vascular function will be studied in order to find possible predictors indicating a positive effect of rehabilitation in cardiovascular system disorders. Molecular studies will be conducted immediately after the last procedure and at 9-month follow-up in the Laboratory of Molecular Studies at the Academy of Physical Education in Katowice.

\section{Cardiac rehabilitation program}

The essential part of the OCR program will be CR based on a protocol developed by an experienced cardiovascular team consisting of physicians and physiotherapists from American Heart of 


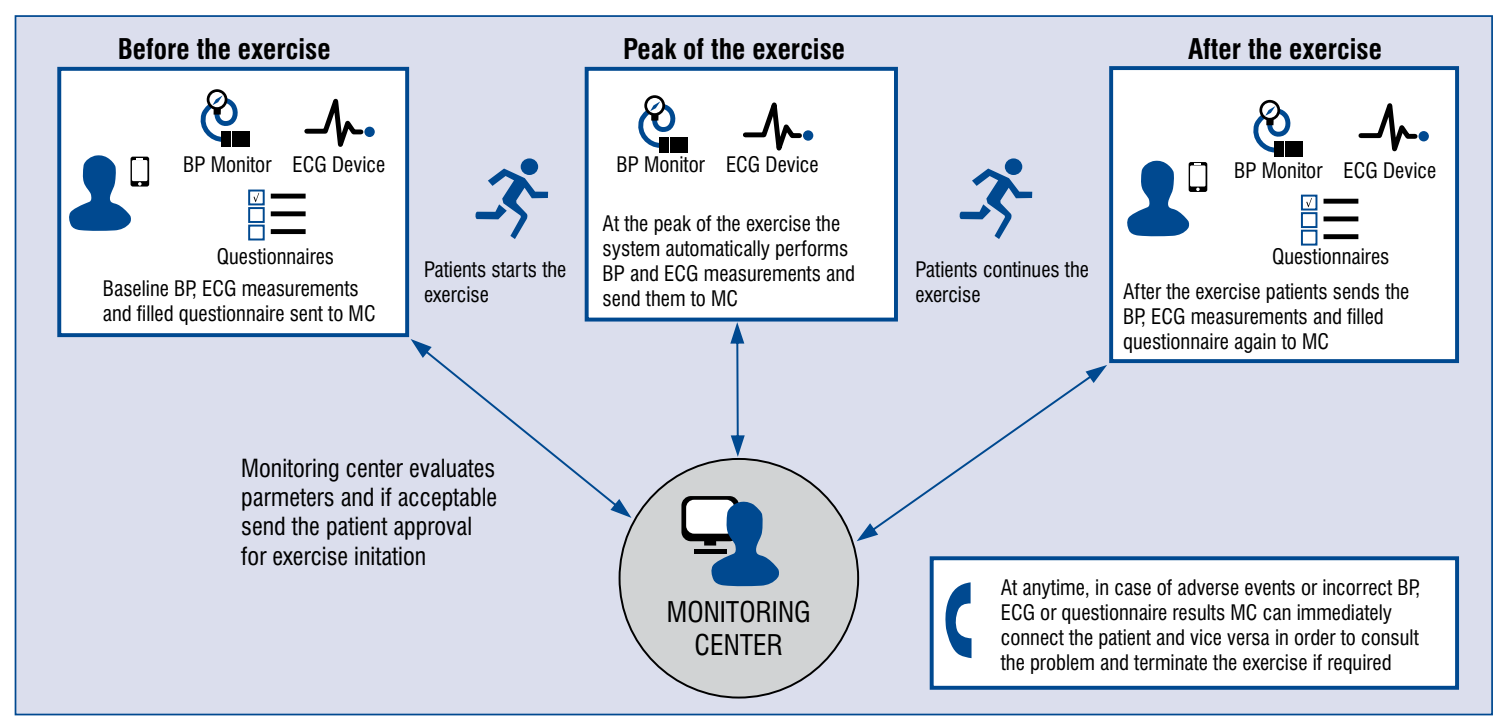

Figure 2. Concept and design of home training utilizing telemonitoring technology; BP — blood pressure; ECG - electrocardiogram; MC - Monitoring Center

Poland SA and the Academy of Physical Education in Katowice. The optimal protocol development will be multi-level. The main steps are presented below:

- First level - qualification for the program of CR: at the beginning of stationary or ambulatory rehabilitation the following data will be analyzed: medical history, resting ECG, baseline blood pressure and heart rate measurements, complete blood count including lipid profile, glucose and electrolyte levels, body weight and body composition measurements. In all patients, cardiac echo will be performed. In addition, all patients will fill out questionnaires to assess their quality of life, physical activity and depression level. The crucial part of this step will be to perform a stress test using a treadmill or bicycle in order to qualify the patient for an adequate rehabilitation model. Before stress test initiation, target heart rate will be calculated using the following formula: $85 \%$ of maximal heart rate $(208-07 \times$ age $)$. In case of beta-blocker intake, heart rate will be adjusted (minus $20-30 \%$ heart rate sub-max). For the treadmill exercise, standard or modified Bruce protocols will be used. During the exercise ECG, blood pressure, heart rate and Borg scale will be used and monitored.

- Second level of rehabilitation (stationary or outpatient CR; duration 2-3 weeks): model A of CR will be designated for patients with the highest exercise tolerance, without angina or any other cardiovascular symp- toms, and who have achieved the level of $\geq 7$ MET or $\geq 100 \mathrm{~W}$ in the stress test. Intensity: $60-85 \%$ of heart rate reserve or 50-75 (80) \% of maximal load. The exercise loads increase gradually through the whole period of rehabilitation. Model B and C of rehabilitation will be designated for patients with low exercise tolerance who achieved at least 6 MET or $75 \mathrm{~W}$ during the initial stress test. Similar to model A, the exercise loads increase gradually. For all patients and all models there will be a possibility for crossover (concerning patients unable to use the TR system). The following types of training have been scheduled: (1) endurance (aerobic), (2) general training to improve a patients' condition, (3) resistance training (aerobic, mixed into the last phase of the period). At the end of this phase all patients qualified to participate in the study group (OCR program) will receive a set of devices for cardiac TR, including a tablet with installed tele-rehabilitation software (designed and produced by the RESTORE Consortium), tele ECG with electrodes (ProPlus SA, Warsaw), blood pressure monitor and training bike (Kettler Polska Sp. z o.o., Poland). Patients will undergo detailed training in order to get familiar with this technology.

- Third level of rehabilitation: (frequency: a minimum of 3 times per week, optimum 5 times per week). Qualification of patients and exercise plan of rehabilitation will be similar to that described in the second level. Exercise 
loads will be modified based on the Borg scale, heart rate (continuous monitoring during physical activity) and stress test performed every 3 months. There will be a possibility to cross over to the other model of rehabilitation. It will also be possible to include additional activities in order to improve patient motivation. These include: jogging, choreotherapy, spinning and other exercises. Furthermore, all patients will be encouraged to participate in periodic street races (including Nordicwalking) over a distance of $5 \mathrm{~km}$. During this phase all patients enrolled in the study group will be obliged to use this novel system of TR according to the instructions and training obtained during the second phase of stationary rehabilitation. The concept and design of home training which utilizes telemonitoring technology is presented in Figure 2. The system allows medical staff to oversee patient parameters including ECG, blood pressure, extent of perceived exertion and quality of life. In addition, it allows monitoring of progress of exercise over time, remotely adjusting the exercise load (if required) and transferring information to the patient by displaying their progress in comparison to others.

Regardless of the intensity of their plan of exercise presented above, all patients will be educated during controlled ambulatory visits with regard to maintaining a proper diet, smoking cessation, risk factor modification and methods of excessive stress reduction. For all patients, echocardiography, stress test and blood analysis will be performed at 1 and 9 months. These tests will be accompanied by a physical examination and mental evaluation using questionnaires identical to the second phase.

\section{Current state of the project \\ (as of August 2018)}

The project commenced in March 2016 and its completion is planned for December 2019. To date, the first phase of the project has been completed. The comprehensive TR platform has been established and successfully tested confirming its efficacy of use, thus enabling progression to the next phase. Recently the enrollment process has begun and 144 patients have been recruited to the study and intravascular imaging with blood sampling for molecular sub-study, which has been performed with the first 10 patients (Fig. 3). Also, first patients enrolled in the study group have already started their TR program that is being monitored by Center for Heart Monitoring built within the structure of the American Heart of Poland. Initial short-term results of the RESTORE project are expected at the end of 2018.

\section{Discussion}

The abovementioned CVD statistics highlight the need for comprehensive solutions in order to reduce the burden of CVD diseases both for affected individuals and the whole medical care system. The state-of-the-art therapy cannot be limited to on-site treatment but rather needs to be combined with a well-thought-out strategy aimed at bringing patients to full recovery, mobilizing them and, through a deep modification of their daily habits, establishing a highly effective preventive strategy for the future. The current guidelines of ESC recommend implementing CR from the very first moment after intervention to ensure accelerated patient convalescence [3]. The value and impact of $\mathrm{CR}$ have been thoroughly checked and confirmed in numerous studies, showing a significant decrease in 1-year mortality [4-6]. Sunamura et al. [8] reported an almost $40 \%$ reduction in overall mortality at 10-year follow-up in a group of CR patients in comparison to non-CR patients.

In most countries $\mathrm{CR}$ is delivered as a supervised center-based program. The necessity to attend scheduled trainings can be restricted by geographical and associated economic barriers, drastically reducing the number of attendees. Therefore, despite such encouraging results regarding CR efficacy, the general aptitude and patient compliance remains unsatisfactory. Studies show that merely $20 \%$ to $50 \%$ (up to $65 \%$ in several countries) of eligible individuals participate in CR in developed countries [19-23]. The causes differ, but decisive actions aiming to resolve this matter are undoubtedly required. Implementing home-based rehabilitation (HBR) could be seen as a partial solution due to improved accessibility. Metanalysis conducted by Buckingham et al. [24] on 17 studies with 2172 patients included, proved non-inferiority of HBR in comparison to center-based CR. What is more, the aspect of patient compliance as well as the probability of completing the whole course, HBR appears to be slightly superior. These findings were later confirmed with two other reviews by Anderson et al. [25] and Zwisler et al. [26], concluding that both forms of rehabilitation are similarly effective for the condition of a patient's health and improvement in quality of life, hinting at a positive impact of increased compliance in the HBR group. However, significant limitations of the 


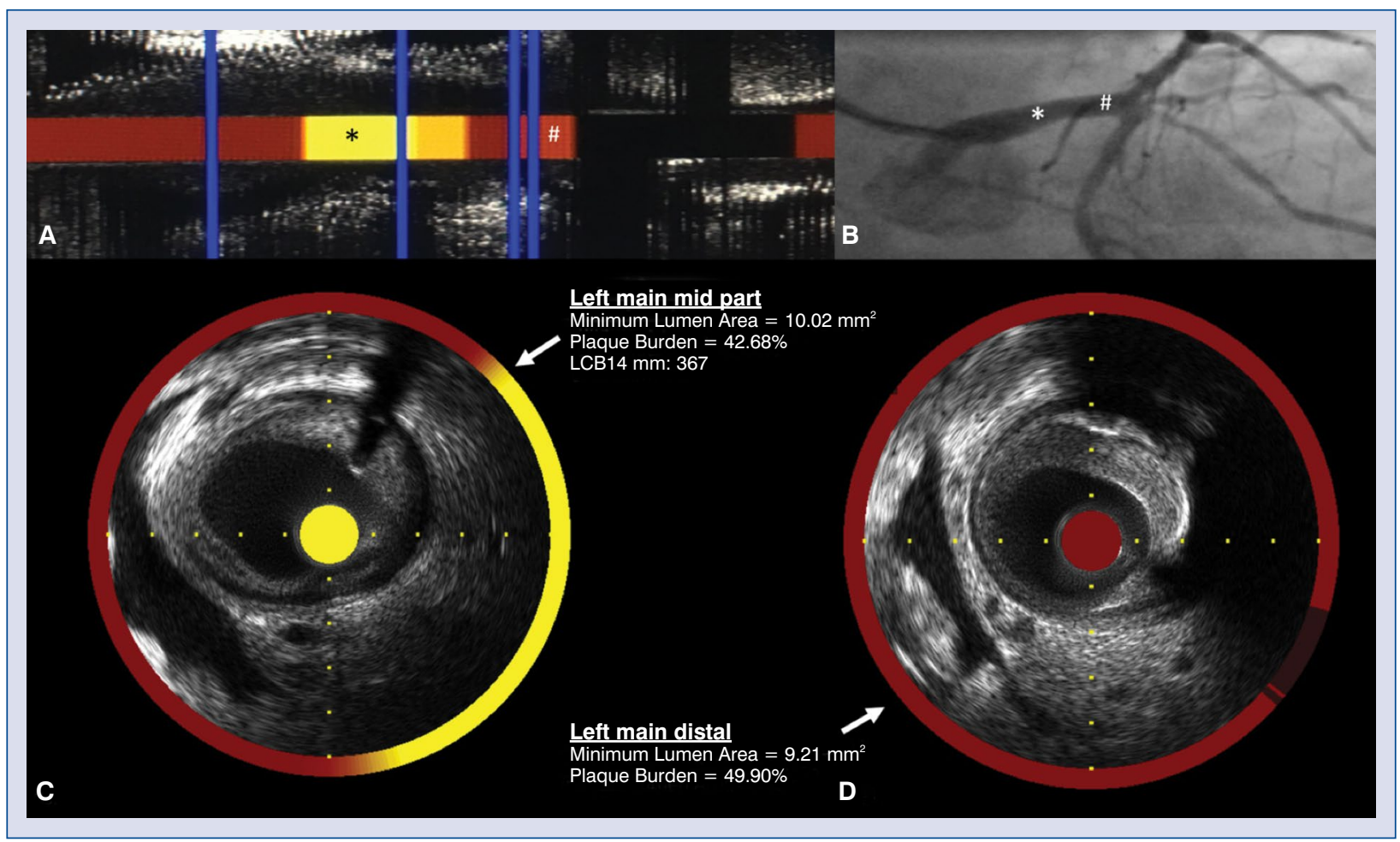

Figure 3. Greyscale intravascular ultrasound (IVUS) with near-infrared spectroscopy (NIRS) imaging of non-treated left main (LM) coronary artery with borderline atherosclerotic lesions performed in first patient enrolled to RESTORE imaging sub-study. A. Longitudinal view of LM with overlapping block chemogram presenting yellow segments with lipid-rich plaques (the asterisk shows mid part of LM) and red segments non-lipidic plaques (the hash shows distal part of LM); B. Angiographic view of LM; C. Cross sectional view of lipid-rich plaque in Segment 4 with maximum lipid core burden index (LCBI) equaled to 367; D. Cross sectional view of non-lipid plaque.

abovementioned studies include a short follow-up time, with only 3 papers exceeding 1 -year observation, as well as the relatively small number of patients included in individual trials, thus requiring further examination.

Yet the question of how to make the impact of $\mathrm{CR}$ long-lasting still remains. Along with completing the CR program, usually spanning several weeks, the supervision is ceased, and the patient is left alone. According to a meta-analysis of 26 randomized clinical trials by ter Hoeve et al. [27], center-based $\mathrm{CR}$ is not sufficient to establish sustainable physical activity habits. Hence, better methods and solutions to provide feedback after completing the core $\mathrm{CR}$ are required.

The RESTORE project was created in 2014 to answer this challenge. The advantages of TR have been studied and its efficacy confirmed, but the low number of trials requires further examination [14-17]. The large number of patients to be included in the present study boosts the significance of this research. Additionally, the authors aim to conduct a long-term observation (obligatory 1-year follow-up with possibility to extend up to a 5 year follow-up) with periodical check-up not only to determine its impact on mortality and morbidity, but to determine whether via constant tele-monitoring, changes in one's lifestyle, physical activity and dietary habits, the positive impact of CR can be maintained. What is more, the imaging sub-study will be performed in order to assess progression, regression or stabilization of atherosclerotic plaques. In parallel a molecular sub-study will evaluate the levels of inflammatory and oxidative stress markers and endothelial function related genes with the aim of finding possible predictors of a positive effect of rehabilitation in cardiovascular system disorders. To enhance patient education and promote healthy living the RESTORE team has launched a program called "Active Heart" that will encourage cardiovascular patients to undertake regular, monitored physical activity. Their dedication will then be gratified by sponsors and all the funds raised in the program will be given to the charity. 


\section{Conclusions}

This novel approach will enable outlining of possible flaws, gain a better understanding of the whole process and draw conclusions resulting in further improvement of optimal CR. Moreover, the underlying concept of the RESTORE project fulfils the expectations of the future role of $\mathrm{CR}$ being simultaneously easily accessible, comprehensive and cost-effective.

\section{Consortium members of the RESTORE project}

- Center for Cardiovascular Research and Development, American Heart of Poland SA;

- The Jerzy Kukuczka Academy of Physical Education in Katowice;

- AGH University of Science and Technology, Faculty of Electrical Engineering, Automatics, Computer Science and Biomedical Engineering;

- Silvermedia SA;

- Fraunhofer-Gesellschaft zur Förderung der angewandten Forschung e.V.;

- Universitätsklinikum Carl Gustav Carus Dresden.

\section{Acknowledgements}

The RESTORE Consortium under the leadership of American Heart of Poland SA has received funding from the Polish National Center for Research and Development under the framework of the strategic program "Prevention practices and treatment of civilization diseases - STRATEGMED”. The total project budget amounts to 3.85 million EUR.

\section{Conflict of interest: None declared}

\section{References}

1. Wilkins E, Wilson L, Wickramasinghe K, et al. European Cardiovascular Disease Statistics 2017. European Heart Network, Brussels. 2017.

2. Gierlotka M, Zdrojewski T, Wojtyniak B, et al. Incidence, treatment, in-hospital mortality and one-year outcomes of acute myocardial infarction in Poland in 2009-2012: Nationwide AMI-PL database. Kardiol Pol. 2015; 73(3): 142-158, doi: 10.5603/ KP.a2014.0213, indexed in Pubmed: 25371307.

3. Piepoli M, Hoes A, Agewall S, et al. 2016 European Guidelines on cardiovascular disease prevention in clinical practice. Rev Esp Cardiol (Engl Ed. 2016; 69(10): 939, doi: 10.1016/j. rec.2016.09.009.

4. Suaya JA, Stason WB, Ades PA, et al. Cardiac rehabilitation and survival in older coronary patients. J Am Coll Cardiol. 2009; 54(1): 25-33, doi: 10.1016/j.jacc.2009.01.078, indexed in Pubmed: 19555836.

5. O'Connor GT, Buring JE, Yusuf S, et al. An overview of randomized trials of rehabilitation with exercise after myocardial infarction. Circulation. 1989; 80(2): 234-244, indexed in Pubmed: 2665973.

6. Jolliffe JA, Rees K, Taylor RS, et al. Exercise-based rehabilitation for coronary heart disease. Cochrane Database Syst Rev. 2000(4): CD001800, doi: 10.1002/14651858.CD001800, indexed in Pubmed: 11034729 .

7. Rauch B, Davos CH, Doherty P, et al. 'Cardiac Rehabilitation Section', European Association of Preventive Cardiology (EAPC), in cooperation with the Institute of Medical Biometry and Informatics (IMBI), Department of Medical Biometry, University of Heidelberg, and the Cochrane Metabolic and Endocrine Disorders Group, Institute of General Practice, Heinrich-Heine University, Düsseldorf, Germany. The prognostic effect of cardiac rehabilitation in the era of acute revascularisation and statin therapy: A systematic review and meta-analysis of randomized and non-randomized studies - The Cardiac Rehabilitation Outcome Study (CROS). Eur J Prev Cardiol. 2016; 23(18): 1914-1939, doi: 10.1177/2047487316671181, indexed in Pubmed: 27777324.

8. Sunamura M, Ter Hoeve N, van den Berg-Emons RJG, et al. Cardiac rehabilitation in patients with acute coronary syndrome with primary percutaneous coronary intervention is associated with improved 10-year survival. Eur Heart J Qual Care Clin Outcomes. 2018; 4(3): 168-172, doi: 10.1093/ehjqcco/qcy001, indexed in Pubmed: 29325067.

9. Giannuzzi P, Mezzani A, Saner H, et al. Working Group on Cardiac Rehabilitation and Exercise Physiology. European Society of Cardiology, Working Group on Cardiac Rehabilitation and Exercise Physiology of the European Society of Cardiology. Secondary prevention through cardiac rehabilitation: position paper of the Working Group on Cardiac Rehabilitation and Exercise Physiology of the European Society of Cardiology. Eur Heart J. 2003; 24(13): 1273-1278, indexed in Pubmed: 12831822.

10. Kotseva K, De Bacquer D, De Backer G, et al. EURObservational research programme: EUROASPIRE. Eur Heart J. 2015; 36(16): 950-951, doi: 10.1093/eurheartj/ehv047, indexed in Pubmed: 25899410.

11. Wenger NK. Current status of cardiac rehabilitation. J Am Coll Cardiol. 2008; 51(17): 1619-1631, doi: 10.1016/j.jacc.2008.01.030, indexed in Pubmed: 18436113.

12. Kotseva K, Wood D, De Backer G, et al. EUROASPIRE Study Group. Cardiovascular prevention guidelines in daily practice: a comparison of EUROASPIRE I, II, and III surveys in eight European countries. Lancet. 2009; 373(9667): 929-940, doi: 10.1016/ S0140-6736(09)60330-5, indexed in Pubmed: 19286092.

13. Suaya JA, Shepard DS, Normand SLT, et al. Use of cardiac rehabilitation by Medicare beneficiaries after myocardial infarction or coronary bypass surgery. Circulation. 2007; 116(15): 16531662, doi: 10.1161/CIRCULATIONAHA.107.701466, indexed in Pubmed: 17893274.

14. Frederix I, Vanhees L, Dendale P, et al. A review of telerehabilitation for cardiac patients. J Telemed Telecare. 2015; 21(1): 45-53, doi: 10.1177/1357633X14562732, indexed in Pubmed: 25475219.

15. Rawstorn JC, Gant N, Direito A, et al. Telehealth exercisebased cardiac rehabilitation: a systematic review and metaanalysis. Heart. 2016; 102(15): 1183-1192, doi: 10.1136/ /heartjnl-2015-308966, indexed in Pubmed: 26936337.

16. Huang K, Liu W, He D, et al. Telehealth interventions versus center-based cardiac rehabilitation of coronary artery disease: A systematic review and meta-analysis. Eur J Prev Cardiol. 2015; 22(8): 959-971, doi: 10.1177/2047487314561168, indexed in Pubmed: 25488550.

17. Hwang R, Bruning J, Morris N, et al. A systematic review of the effects of telerehabilitation in patients with cardiopulmo- 
nary diseases. J Cardiopulm Rehabil Prev. 2015; 35(6): 380389, doi: 10.1097/HCR.0000000000000121, indexed in Pubmed: 26034937.

18. Pocock S, Bueno H, Licour M, et al. Predictors of one-year mortality at hospital discharge after acute coronary syndromes: A new risk score from the EPICOR (long-tErm follow uP of antithrombotic management patterns In acute CORonary syndrome patients) study. Eur Heart J Acute Cardiovasc Care. 2015; 4(6): 509-517, doi: 10.1177/2048872614554198, indexed in Pubmed: 25301783.

19. NACR. The national audit of cardiac rehabilitation annual statistical report 2015. London: British Heart Foundation. 2015.

20. Menezes AR, Lavie CJ, Milani RV, et al. Cardiac rehabilitation in the United States. Prog Cardiovasc Dis. 2014; 56(5): 522-529, doi: 10.1016/j.pcad.2013.09.018, indexed in Pubmed: 24607017 .

21. Jelinek MV, Thompson DR, Ski C, et al. 40 years of cardiac rehabilitation and secondary prevention in post-cardiac ischaemic patients. Are we still in the wilderness? Int J Cardiol. 2015; 179: 153-159, doi: 10.1016/j.ijcard.2014.10.154, indexed in Pubmed: 25464436.

22. Forman DE, Sanderson BK, Josephson RA, et al. American College of Cardiology's Prevention of Cardiovascular Disease Section. Heart Failure as a Newly Approved Diagnosis for Cardiac
Rehabilitation: Challenges and Opportunities. J Am Coll Cardiol. 2015; 65(24): 2652-2659, doi: 10.1016/j.jacc.2015.04.052, indexed in Pubmed: 26088305.

23. Altenhoener T, Leppin A, Grande G, et al. Social inequality in patients' physical and psychological state and participation in rehabilitation after myocardial infarction in Germany. Int J Rehabil Res. 2005; 28(3): 251-257, indexed in Pubmed: 16046919.

24. Buckingham SA, Taylor RS, Jolly K, et al. Home-based versus centre-based cardiac rehabilitation: abridged Cochrane systematic review and meta-analysis. Open Heart. 2016; 3(2): e000463, doi: 10.1136/openhrt-2016-000463, indexed in Pubmed: 27738516.

25. Anderson L, Sharp GA, Norton RJ, et al. Home-based versus centre-based cardiac rehabilitation. Cochrane Database Syst Rev. 2017; 6: CD007130, doi: 10.1002/14651858.CD007130.pub4, indexed in Pubmed: 28665511.

26. Zwisler AD, Norton RJ, Dean SG, et al. Home-based cardiac rehabilitation for people with heart failure: A systematic review and meta-analysis. Int J Cardiol. 2016; 221: 963-969, doi: 10.1016/j. ijcard.2016.06.207, indexed in Pubmed: 27441476.

27. ter Hoeve N, Huisstede BMA, Stam HJ, et al. Does cardiac rehabilitation after an acute cardiac syndrome lead to changes in physical activity habits? Systematic review. Phys Ther. 2015; 95(2): 167-179, doi: 10.2522/ptj.20130509, indexed in Pubmed: 25278337. 